\title{
ATIVISMO JUDICIAL E A INSTRUMENTALIDADE DO PROCESSO: UM DIÁLOGO COM GEORGES ABBOUD E GUILHERME LUNELLI A PARTIR DA OBRA DE CÂNDIDO RANGEL DINAMARCO
}

\section{JUDICIAL ACTIVISM AND INSTRUMENTALITY OF THE PROCEDURE: A DIALOGUE WITH GEORGES ABBOUD AND GUILHERME LUNELLI FROM THE WORK OF CÂNDIDO RANGEL DINAMARCO}

Carolina Nobre Castello Branco ${ }^{1}$

Nestor Eduardo Araruna Santiago ${ }^{2}$

\begin{abstract}
RESUMO
Este artigo tem como objetivo investigar se a teoria da instrumentalidade do processo, elaborada por Cândido Rangel Dinamarco, contribuiu para o ativismo judicial. De natureza qualitativa, tem por objeto a crítica à teoria da instrumentalidade do processo publicada em um artigo científico de autoria de Georges Abboud e Guilherme Lunelli. Mediante uma abordagem dialética, o estudo se concentra em destacar os principais argumentos críticos dos autores para fins de avaliação e confrontação teórica. Inicialmente é feita uma análise da relação apresentada pelos autores entre o ativismo judicial e a instrumentalidade do processo, para compreender os argumentos que fomentaram suas conclusões. Posteriormente, avaliou-se o constitucionalismo contemporâneo, evidenciando-se suas influências na evolução do sistema processual e no conceito de jurisdição. Por fim, o trabalho se concentra em demonstrar os motivos pelos quais o instrumentalismo deve ser compreendido como uma forma de obter o acesso à justiça e não como um estímulo ao ativismo judicial.
\end{abstract}

Palavras-chave: Ativismo judicial. Instrumentalidade. Processo. Jurisdição. Acesso à Justiça. Cândido Rangel Dinamarco.

\begin{abstract}
This paper aims to investigate whether the instrumentality of the procedure theory contributes to judicial activism. As a qualitative nature research, its object is the criticism to the instrumentality of the procedure theory published in a scientific paper written by Georges Abboud and Guilherme Lunelli. Through a dialectical approach, the study focuses on highlighting the main critical arguments of the authors for purposes of theoretical assessment

\footnotetext{
${ }^{1}$ Doutora em Direito Constitucional pela Universidade de Fortaleza (UNIFOR). Mestre em Direito Constitucional e Especialista em Direito Processual pela Pontifícia Universidade Católica de São Paulo (PUC-SP). Advogada. Afiliação: Universidade de Fortaleza, Ceará. ORCID: https://orcid.org/0000-0002-3652-598X. Lattes: http://lattes.cnpq.br/7924844710242479. E-mail: carolinancb@gmail.com

${ }^{2}$ Doutor em Direito (UFMG, 2005). Professor Titular do Programa de Pós-Graduação em Direito Constitucional da Universidade de Fortaleza, Ceará. Professor do Curso de Graduação em Direito da Faculdade de Direito da Universidade Federal do Ceará. Afiliação: Universidade de Fortaleza, Ceará. Lattes: http://lattes.cnpq.br/4516474580462451. ORCID: https://orcid.org/0000-0002-2479-7937 E-mail: nestoreasantiago@gmail.com
} 
and confrontation. Initially an analysis of the relationship presented by the authors between judicial activism and the instrumentality of the process have been made, in order to understand the arguments that fostered their conclusions. Subsequently, the contemporary constitutionalism was evaluated, evidencing its influences on the evolution of the procedural system and the concept of adjudication. Finally, the work focuses on demonstrating why instrumentalism should be understood as a way to gain access to justice rather than as a stimulus to judicial activism.

Keywords: Judicial activism - Instrumentality - Procedure - Adjudication - Access to Justice

\section{INTRODUÇÃO}

Quando Cândido Rangel Dinamarco publicou 'A Instrumentalidade do Processo', o desenvolvimento da doutrina processual tinha como objeto principal de estudo o processo, a formação da relação jurídica processual e as condições da ação. Em 1987, a publicação da teoria da instrumentalidade de Dinamarco representou uma revolução na história processual brasileira, pois colocou em destaque a função jurisdicional, posicionando o processo como um instrumento de realização da justiça.

Pela análise de Dinamarco, seria necessário repensar o Direito Processual para aproximá-lo das realidades da vida. Seu formalismo exacerbado proporcionou um isolamento e uma mistificação que tornava a atividade jurisdicional desconectada dos seus resultados. Por essa razão, é possível afirmar que a instrumentalidade do processo representa para a doutrina processual brasileira o marco para a mudança no conceito de jurisdição, sobretudo porque observa o processo como ferramenta para obtenção do direito material e relativiza o formalismo processual, foco dos estudos da doutrina até então desenvolvida.

Por outro lado, a flexibilidade das normas processuais e a mitigação de regras para a obtenção da justiça pode também provocar um indesejável efeito adverso: a insegurança jurídica. O formalismo processual seria, assim, garantia constitucional intrínseca ao processo e fundamental para a sua validade. É por meio do formalismo que o princípio da igualdade, da paridade de formas e da imparcialidade do juiz também são garantidos no processo, vez que fica assegurada a prestação jurisdicional de forma equitativa, sem qualquer distinção em razão do fato ou das partes.

Por esse aspecto, entender o processo como um instrumento da justiça mediante a flexibilização de suas normas poderia fomentar o surgimento de decisões contrárias à norma processual, em ofensa aos princípios da igualdade e da segurança jurídica. A doutrina com 
frequência identifica esse tipo de atuação como ativismo judicial e representa, em suma, a atuação do magistrado não apenas à revelia da lei, mas também mediante a utilização pouco criteriosa de princípios - constitucionais ou não - na elaboração de decisões, evidenciando-se o cariz subjetivo da decisão judicial conforme a vontade do julgador.

Contudo, há consistente divergência na doutrina no que diz respeito ao conceito do ativismo judicial, assim como dos limites e possibilidades da atividade jurisdicional, o que torna essencial a discussão apropriada de conceitos estruturantes que envolvem o debate. No caso, compreender em que consiste o ativismo judicial parece ser um ponto de partida essencial para relacioná-lo com a instrumentalidade do processo, mas é também por meio do entendimento adequado da teoria da instrumentalidade que será possível identificar alguma relação entre esta teoria e o fenômeno do ativismo.

Assim, o principal objeto deste trabalho é avaliar a crítica direcionada à teoria da instrumentalidade do processo desenvolvida por Georges Abboud e Guilherme Lunelli no artigo "Ativismo judicial e instrumentalidade do processo", publicada no volume 242 da Revista de Processo no ano de 2015. No entendimento dos autores, os ideais da teoria de Dinamarco conduzem a um modelo ativista de magistratura que seria questionável à luz do Estado de Direito.

No decorrer deste estudo será demonstrado que a teoria da instrumentalidade do processo, na verdade, protege o Estado de Direito Constitucional, pois a sua efetividade depende da utilização de três escopos: jurídico, político e social. O escopo jurídico consiste na atuação da vontade concreta do direito; o escopo social é a capacidade de educar e pacificar com justiça; e o político deriva da atuação da jurisdição como poder estatal, e não pode ser exercido fora do âmbito constitucionalmente delineado. Portanto, não haveria espaço para a atuação do juiz fora da moldura elaborada pelo constituinte, de modo que o desenvolvimento do processo à revelia das normas legais e constitucionais configura nítida ilegalidade.

Nesse sentido, a pesquisa tem base bibliográfica, com caráter qualitativo. Para tanto, além da análise do artigo desenvolvido por Georges Abboud e Guilherme Lunelli e da obra de Cândido Rangel Dinamarco, procura-se amparo ainda em outros trabalhos científicos e obras doutrinárias relacionados à temática explorada para demonstrar que a teoria da instrumentalidade não compreende uma porta de entrada para a atuação do juiz de forma ativista pois representa, mediante a efetiva observância dos seus escopos, a realização da Constituição por meio da atividade jurisdicional. A ideia é provocar o debate, pouco usual na doutrina jurídica brasileira, como forma de desenvolver a contraposição de ideias. 
Desse modo, o método é dialético quanto à abordagem, pois realiza um enfrentamento das afirmações de Abboud e Lunelli com as explicações de Dinamarco na construção da sua teoria, de modo a permitir um desenvolvimento das ideias de ativismo e instrumentalidade sem a pretensão totalizante. Nesse intuito, o texto apresenta transcrições literais, embora não seja um recurso usual dos autores. A intenção é explicitar os argumentos para promover uma compreensão adequada das críticas apresentadas.

Formalmente, o estudo foi desenvolvido em três partes. De início, o artigo de Georges Abboud e Guilherme Lunelli foi analisado para compreender a relação apresentada do ativismo judicial com a teoria da instrumentalidade, bem como os argumentos que sustentam suas conclusões. A partir de então, procurou-se avaliar o constitucionalismo contemporâneo para perceber suas influências no direito processual e na ideia de centralidade de jurisdição proposta por Dinamarco, relacionando-a com o fenômeno do ativismo judicial.

Por fim, confrontou-se os argumentos dos autores com as explicações de Dinamarco destacadas de sua obra 'A instrumentalidade do Processo'. A partir da identificação de pontos estruturantes da teoria da instrumentalidade, as características do ativismo judicial foram confrontadas para afastar a ideia de que o instrumentalismo sustenta o ativismo, ressaltando-se o papel dos escopos processuais como elementos conformadores da atuação jurisdicional idealizada pelo autor.

É oportuno ainda esclarecer que apesar de se tratar de um estudo realizado sob a perspectiva crítica, o cenário no qual estes autores pretendem dialogar ainda se apresenta obscuro e carrega certa misticismo. Há intenso debate jurídico favorável e contrário ao ativismo judicial, um fenômeno contemporâneo cuja compreensão ainda não encontra consenso doutrinário.

\section{ATIVISMO JUDICIAL E INSTRUMENTALIDADE DO PROCESSO EM ABBOUD E LUNELLI}

Em artigo, os professores Georges Abboud e Guilherme Lunelli (2015) defenderam que a instrumentalidade do processo é capaz de fomentar o ativismo, dando ênfase à sua existência e sustentando a sua aplicação. Partem da premissa de que o ativismo é uma extrapolação dos limites na atividade judicante caracterizada por um problema eminentemente hermenêutico, 
relacionado à invasão de elementos metajurídicos no processo interpretativo-decisório. Por fim, concluem que o ativismo é, na verdade, uma faceta da discricionariedade.

Após uma breve exposição da teoria da instrumentalidade, os autores tecem críticas estruturadas em três pontos principais: a falácia do juiz 'antena', a pacificação com justiça e as escolhas interpretativas diante de uma legislação democraticamente instituída. Para os autores, a teoria da instrumentalidade "acaba apostando, ainda que sem o fazer expressamente, em condutas ativistas e acarreta manifestos desserviços à vivência democrática.” (ABBOUD; LUNELLI, 2015, p. 27).

Basicamente, a preocupação dos autores aponta para o problema da confiança demasiada que a instrumentalidade deposita no julgador. Por conferir liberdade interpretativa ao magistrado a teoria de Dinamarco aposta em um juiz capaz de captar os anseios sociais e decidir com seus próprios sentimentos sobre justiça. Como o senso de justiça é um conceito plurissignificativo, a obtenção de uma decisão justa dependeria de um critério livremente escolhido pelo julgador.

Segundo Abboud e Lunelli (2015), a aposta de Dinamarco é na juristocracia e no governo dos bons juízes, pois haveria uma extrema confiança da doutrina instrumentalista de que os magistrados detêm o potencial de extrair as legítimas expectativas da sociedade, funcionando como uma espécie de 'antena' capaz de captar todos os anseios sociais dominantes para a construção de suas decisões:

[...] já no primeiro capítulo de sua obra, Dinamarco deixa bem claro qual o papel deve ser confiado à magistratura na nova ordem constitucional-processual e, de tais apontamentos, retira o fio condutor para todo o seu estudo. Parece haver uma aposta no mito do bom governo dos juízes, ou seja, na crença da Juristocracia como paradigma adequado para superarmos nossas mazelas. (ABBOUD; LUNELLI, 2015.p. 27)

Outra grande aposta da doutrina instrumentalista seria a realização da justiça por meio do processo. Para os autores, apesar de ser um escopo da atividade jurisdicional, a preocupação de Dinamarco com o elemento justiça não foi suficiente para esclarecer a concepção de justiça adotada. Por essa razão, concluem que para os instrumentalistas apostam no solipsismo porque a percepção do valor de justiça será derivada de apreciação subjetiva do julgador. (ABBOUD; LUNELLI, 2015, p. 28)

Dessa forma, entendem que a instrumentalidade oferece "aposta explícita na discricionariedade do julgador no momento da interpretação da lei” (ABBOUD; LUNELLI, 2015, p. 29), pois compete ao julgador escolher livremente a interpretação que lhe pareça mais 
justa. Por meio de uma explicação simplificada do escopo jurídico da teoria de Dinamarco, afirmam a existência de um "total desapego da teoria instrumentalista à lei democraticamente posta" (ABBOUD; LUNELLI, 2015, p. 30). Em síntese, a teoria da instrumentalidade do processo valorizaria mais o sentimento de justiça e a subjetividade do julgador do que o processo legislativo-democrático.

Entretanto, ainda que as preocupações dos autores relacionadas ao ativismo judicial mereçam consideração, não é possível afirmar, em tão pouco espaço retórico e de forma tão categórica, que "as posturas ativistas são estimuladas pela teoria instrumentalista do processo" (ABBOUD; LUNELLI, 2015, p. 30). Isso porque a compreensão por dedução de que a teoria instrumentalista "acaba apostando" (ABBOUD; LUNELLI, 2015.p. 27) em condutas ativistas e prejudica a convivência democrática, configura uma ideia desvirtuada dos propósitos da teoria de Dinamarco, construída mediante a observância de critérios técnicos capazes de controlar a construção da decisão pelo juiz, conforme se observará adiante.

\section{OS INFLUXOS DO CONSTITUCIONALISMO CONTEMPORÂNEO NO DIREITO PROCESSUAL}

Após 1988, com a promulgação da Constituição Federal, um novo ordenamento jurídico foi inaugurado pautado em direitos e garantias fundamentais. A partir de então iniciou-se um processo de modificação da compreensão existente sobre o princípio da legalidade. Além de regras, identifica-se no texto constitucional normas capazes de guardar valores fundamentais que otimizam toda a estrutura do ordenamento jurídico para adequá-lo a sua moldura: os princípios.

Sabe-se que a Jurisdição surgiu da necessária separação dos poderes quando da reorganização dos papéis do Estado na sociedade, após as revoluções liberais. O princípio da legalidade estabeleceu limites à atuação estatal e possibilitou o desenvolvimento do direito como ciência, dados os aportes filosóficos do positivismo.

Mas a compreensão estática e formal do direito, identificando-o com a produção de normas do Poder Legislativo, estaria sendo gradualmente substituída por uma pluralidade de fontes, reconhecendo-se a sociedade aberta dos intérpretes da Constituição, concepção trazida por Peter Härbele (2002) que revela um modelo de interpretação mais democrático para incluir nessa atividade todos aqueles que vivem no contexto de suas normas. 
Portanto, em razão da Constituição de 1988, o direito brasileiro vem sofrendo profundas mudanças responsáveis pelo estabelecimento de um novo paradigma na teoria jurídica. Identifica-se o surgimento de fenômenos diferentes, mas reciprocamente implicados, consistentes no reconhecimento do efeito da força normativa dos princípios jurídicos e valorização de sua importância para o processo, rejeição ao formalismo, utilização mais frequente de estilos abertos de raciocínio jurídico, reaproximação entre o Direito e a Moral, constitucionalização do direito e judicialização da política (SARMENTO, 2010).

Essas transformações foram identificadas pela doutrina pátria como neoconstitucionalismo, pois consistiam em uma nova forma de compreender a Constituição para revelar a possibilidade do exercício da sua força normativa e a aplicação imediata dos princípios constitucionais na interpretação jurídica. Conforme explica Sarmento (2010), a palavra 'neoconstitucionalismo' é um conceito desenvolvido na Espanha e Itália com muitos juristas no Brasil que a ele aderiram, mas há uma ampla diversidade de posições jusfilosóficas que dificulta a tarefa de defini-lo como uma única concepção clara e coesa. Há, na verdade, vários neoconstitucionalismos.

Para alguns, a doutrina neoconstitucionalista seria, sobretudo, uma política constitucional, pois permite indicar como o direito deve ser e não simplesmente como ele é. Essa é a ideia apresentada por Écio Duarte e Suzanna Pozzolo (2010), ao afirmarem que o neoconstitucionalismo demanda exigências interpretativas dependentes do modo de conceber a Constituição, em determinado Estado de Direito Constitucional. O fenômeno seria caracterizado pelos seguintes traços: a) adoção de um modelo prescritivo de Constituição como norma; b) adoção da tese de que o direito é composto também por princípios; c) utilização das técnicas de ponderação e balanceamento; e d) tarefas de integração da jurisprudência e de tarefas pragmáticas à Teoria do Direito.

Prontamente, as críticas surgiram. Para Galvão (2014), as teses 'neoconstitucionalistas' enfatizam a possibilidade de modificação da sociedade pela via do Poder Judiciário, o que proporcionou uma maior intervenção judicial por meio da interpretação criativa. Trata-se de uma utilização progressista da jurisdição constitucional a partir de uma leitura abstrata de princípios, de modo que, ao invés de se preservar os princípios constitucionais estabelecidos, “à Corte é designada a função de criticar moralmente a sociedade, ensejando decisões proféticas sobre o conteúdo do texto constitucional" (GALVÃO, 2014, p. 103).

Dessa forma, a aplicação do direito baseado em princípios, sem fundamentação normativa e com critérios subjetivos de ponderação, pode levar ao desprezo de importantes 
regras de interpretação indispensáveis para proporcionar a segurança jurídica e a imparcialidade das decisões judiciais. Como bem colocado por Pugliesi e Brandão (2019), se um ato de poder é capaz de fundar um Estado, significa que as normas jurídicas deveriam conceder uma condição isonômica, pois destinam-se a todos, sem exceções, até mesmo para legisladores e juízes.

No modelo proposto pelo Estado de Direito, especialmente considerando o seu aspecto democrático, impõe-se a aplicação da lei de modo neutro para que a interpretação busque o significado da norma no contexto social, mas não a materialização do pensamento subjetivo do intérprete. Segundo Streck e Saldanha (2013), ainda há um estranhamento com relação à Constituição e o Direito, pois a atuação da jurisdição constitucional possui, muitas vezes, papel contramajoritário, o que resulta em uma percepção equivocada de que o constitucionalismo é contrário à democracia. A ideia de aplicação de princípios acabou revelando pontos de especial preocupação dos juristas: a subjetividade das decisões, o excesso de confiança no intérprete e a insegurança jurídica provocada pela ausência de parâmetros formais.

Tais preocupações também aparecem no âmbito infraconstitucional porque as influências do constitucionalismo contemporâneo não repercutem apenas na atuação da jurisdição constitucional, mas também na aplicação do direito vivenciada por qualquer juiz ou tribunal. Perceba-se que, a partir de possibilidades trazidas pelo 'neoconstitucionalismo' juízes passariam a justificar a sua atuação na ideia de concretização da Constituição.

Streck (2014) observa que a tradição jurídica brasileira estava assentada em um modelo liberal-individualista, em que não havia lugar para direitos de segunda e terceiras dimensões. Isso fez com que os juízes brasileiros recepcionassem as teorias estrangeiras de modo acrítico, apostando-se no protagonismo dos juízes sustentado por um incentivo doutrinário pautado na jurisprudência de valores e na teoria da argumentação de Robert Alexy.

Tal prática logo estabeleceu uma tendência na forma de atuar dos juízes preocupados com a realização da justiça, o que resultou na utilização desmedida de princípios e favoreceu a prevalência do aspecto subjetivo do juiz como elemento de construção da decisão jurisdicional. Desse modo, o juiz partiria de convicções internas para aplicar os valores ao caso e obter aquilo que ele, pessoalmente, entende por justiça.

Identificada na doutrina como 'ativismo judicial', esse tipo de conduta faz preponderar a função ativa do juiz na solução do caso concreto a partir de princípios, ignorando a existência de regras jurídicas específicas que eventualmente dispusessem em sentido contrário do senso de justiça percebido pelo juiz. Segundo Streck (2014) o ativismo está relacionado com 
panprincipiologismo, fenômeno caracterizado pela invasão de centenas de princípios na interpretação e aplicação do direito, fragilizando seu grau de autonomia e a força normativa da Constituição.

Por outro lado, o princípio da legalidade, tal como estabelecido no Estado Liberal, sofreu mudanças de compreensões dada a pluralidade de fontes do direito desenvolvida com o advento do pós-positivismo. Como os textos constitucionais são principiológicos, a lei não poderia mais ser compreendida como a única fonte do direito. Desse modo, os princípios, a jurisprudência e a doutrina formariam, ao lado da lei, um sistema composto de dados capazes de dar suporte interpretativo para o juiz construir a sua decisão no caso concreto.

O problema seria apostar de modo acrítico nas ideias 'neoconstitucionalistas' trazidas para o Brasil sem observar o processo natural de desenvolvimento do constitucionalismo brasileiro a partir das expectativas de 1988. Assim, é preferível afirmar que foi o 'neoconstitucionalismo', e não uma teoria sobre a instrumentalidade do processo, que permitiu uma leitura subvertida deste momento constitucional, porque a Constituição brasileira, mesmo com toda a sua força normativa, não entrega aos poderes constituídos liberdade de atuação à revelia da lei. Para Copatti (2019, p. 2433) o ativismo judicial é uma das faces do 'neoconstitucionalismo'.

Portanto, o ativismo judicial se revela mais como um sintoma indesejado, mas naturalmente derivado do processo de ajuste da prática jurídica aos novos padrões constitucionais do que propriamente uma doutrina ou categoria filosófica a ser seguida por escolha. Como um sintoma, a conduta ativista deve ser remediada e evitada, pois não caracteriza a postura idealizada pela Constituição Federal de 1988.

Segundo Jorge (2014, p. 511-513), o ativismo judicial está relacionado com a transformação do papel do Poder Judiciário ocorrida nos últimos duzentos anos, pois os juízes deixaram de ser meros aplicadores da lei para se tornar coautores do significado da norma. Seria, assim, uma decorrência lógica do pós-positivismo, este caracterizado pela normatização de conteúdos axiológicos por meio dos princípios cujos conteúdos não são imediatamente definíveis.

O direito processual não tinha como passar imune a todas essas transformações sofridas pela metodologia jurídica no constitucionalismo contemporâneo. O reconhecimento da força normativa da Constituição tornou possível a mudança dogmática do Estado Legislativo para o Estado Constitucional que fez ampliar o objeto do direito processual. 
Para Dinamarco, a preponderância metodológica da jurisdição corresponde à visão publicista do sistema, pois o Estado utiliza o processo como instrumento para o cumprimento de seus objetivos. Desse modo o processo alcança seu significado político porque atua como um sistema aberto voltado para preservar os valores sociais afirmados pelo Estado e a jurisdição está na sua estrutura de poder (DINAMARCO, 2005).

Nesse contexto, a teoria instrumentalista representa o início do desenvolvimento de uma nova fase da ciência processual capaz de identificar a atividade jurisdicional com os objetivos do Estado Constitucional.

\subsection{A CENTRALIDADE DA JURISDIÇÃO EM DINAMARCO E O ATIVISMO JUDICIAL}

O direito processual deve ser estudado com base na Jurisdição, na Ação, na Defesa e no Processo. Tais elementos estruturantes são responsáveis pela formação de uma base comum que fundamenta o desenvolvimento da ciência processual porque é por meio do conhecimento dos seus respectivos conceitos que se forma a sistemática necessária para a sua compreensão.

É factível afirmar que não há jurisdição sem processo. Por mais óbvia que essa afirmação pareça ser, há uma razão lógica para ser feita: a concepção do processo como um instrumento depende, necessariamente, da identificação da finalidade da jurisdição, sendo que tanto a jurisdição como o processo justificam a sua construção a partir da existência do direito de ação e do direito de defesa, constitucionalmente garantidos no Estado Democrático de Direito. A permeabilidade desses elementos é justificada na compreensão da ciência processual como um sistema constantemente retroalimentado pelos conceitos que os envolvem.

Por serem responsáveis pelo desempenho de certas funções no sistema processual, cada um desses elementos precisa ser igualmente estudado e compreendido. No entanto, na teoria da instrumentalidade, Dinamarco (2005) propôs que a jurisdição tivesse papel central no seu desenvolvimento. Ele explica que não se trata de inovar por inteiro para chegar a soluções originais por meio da transgressão de regras, mas sim reconstruir o pensamento dos processualistas e interpretar os rumos atuais da ciência processual para entregar "uma enfática mensagem ao espírito de todos quantos manipulam o instrumental da Justiça.” (DINAMARCO, 2005, p. 12). 
Dinamarco pretendeu chamar atenção para a necessidade de uma revisão do modo como os juristas encaravam o processo mediante o estabelecimento de uma nova perspectiva necessária para contrapor a metodologia de estudo "insensível à realidade do mundo", pautada na fixação de estruturas e no aprimoramento de conceitos. Sua proposta baseia-se em definir o próprio sistema processual como objeto de estudo, mas examinado por um ângulo externo, com finalidade de desenvolvê-lo de forma capaz de fixar objetivos e perseguir resultados (DINAMARCO, 2005, p. 11).

Como a crítica à teoria da instrumentalidade parte da ideia de que a centralidade da jurisdição fomenta uma interpretação solipsista do magistrado, convém compreender melhor em que consiste essa centralidade e como ela pode se desenvolver no contexto do constitucionalismo inaugurado com a Constituição Federal de 1988.

É preciso esclarecer que Dinamarco concluiu sua proposta em 1986, pouco antes da Constituição de 1988, momento em que ainda era justificável o estudo do direito processual baseado em concepções privatistas, sobretudo diante da influência do positivismo jurídico operante na metodologia da época.

Contudo, a manutenção desse tipo de abordagem da ciência processual desconecta o processo da realidade dos fatos, enfraquece seu objetivo e desvirtua a sua aplicação. Não é raro observar a preocupação doutrinária com o conceito de jurisdição a partir de Carnelutti e Chiovenda, muitas vezes combinados de modo a conferir a ideia de complementaridade. Porém, Carneiro (2008) revela que a conjugação de conceitos foi necessária para adequar a prestação jurisdicional aos padrões do ordenamento jurídico vigente.

Portanto, as teorias da jurisdição devem refletir valores e ideias das épocas, razão pela qual os pensamentos de Chiovenda e Carnelutti são importantes apenas quando se faz uma abordagem crítica em comparação com o direito atual, vez que não guardam relação com o Estado contemporâneo (MARINONI, 2014).

Desse modo, ainda que os conceitos de jurisdição desenvolvidos por Chiovenda e Carnelluti tenham importância para o desenvolvimento da ciência processual, são insuficientes para explicar a atividade jurisdicional na contemporaneidade. Na perspectiva de Dinamarco (2005), é preciso compreender a abertura do sistema processual para absorver influências da política e da sociologia, pois o direito tem um modo de ser propenso ao formalismo e ao isolamento.

Ao posicionar a jurisdição como centro do desenvolvimento do sistema processual, Dinamarco objetivou evidenciar os exageros de uma metodologia que ainda insistia em afirmar 
a autonomia do direito processual e conceituar seus institutos fundamentais sem atentar para os resultados que o sistema estava entregando.

Dessa forma, compreende a instrumentalidade como o terceiro momento metodológico do direito processual (DINAMARCO, 2005, p. 22), pois não é mais justificável que o processualista moderno investigue conceitos já estudados e compreendidos, sendo fundamental que agora se preocupe com resultados práticos.

Se a jurisdição é uma das funções do Estado é dever do direito processual reconhecer a adequação do conceito de jurisdição para que seja possível alcançar os objetivos fundamentais do Estado. Portanto, a jurisdição precisa a ser compreendida a partir de uma perspectiva finalística. A doutrina reconhece, especialmente após o Novo Código de Processo Civil, a finalidade institucional de atuar ou realizar a tutela por meio da identificação e da imposição do direito de forma que sejam efetivamente materializados pelo Poder Judiciário (MEDINA, 2015).

Por outro lado, a doutrina processual moderna também compreende que o Estado Constitucional deu novo conteúdo ao princípio da legalidade, causando transformações na própria concepção de direito. Dessa forma, o princípio da legalidade incorporou elemento qualificativo substancial para evidenciar a subordinação da lei aos valores e princípios constitucionais. Essa modificação na forma de compreensão do princípio da legalidade em legalidade substancial afeta também as próprias concepções de jurisdição (MARINONI, 2014).

Essas modificações da jurisdição e a posição central que ocupa na ciência processual pode ter levado a algumas compreensões equivocadas sobre as possibilidades da atuação jurisdicional e, neste aspecto, as preocupações de Abboud e Lunelli (2015, p. 24) com o fenômeno do ativismo judicial precisam ser consideradas.

No entendimento dos autores, o problema do ativismo sempre esteve relacionado aos limites entre a atividade interpretativa e a atividade criativa do julgador, o que acaba por gerar o problema da discricionariedade:

E é nesse ponto que desponta o problema da discricionariedade, das convicções pessoais e, por consequência, do ativismo judicial: pode o sentido do texto constitucional (ou mesmo das leis) resumir-se a um mero juízo de conveniência do julgador? Será que o sentido dos textos está à disposição do intérprete, para que este "pince" - ou mesmo crie - aquele que, a depender de suas convicções ideológicas, mais lhe agrade? (ABBOUD; LUNELLI, 2015, p. 24).

As respostas para estes questionamentos devem ser negativas. Neste ponto, concordase com a posição dos autores que chamam atenção para o fato de que, no momento da 
construção da norma, o julgador pudesse estar autorizado a utilizar os seus valores, convicções e ideologias em suas decisões, para então impor estas a toda sociedade. Certamente, essa não é a resposta democrática constitucionalmente prevista para a atuação do Judiciário.

O conceito de ativismo judicial desenvolvido pelos autores deriva do direito norteamericano, berço do seu nascimento, que permite compreender uma apropriação, por Parte do Judiciário, de outras funções estatais. A atividade jurisdicional passa a ser orientada pelos resultados, ideologizada e subjetiva. Assim, o ativismo é um problema essencialmente hermenêutico relacionado a invasão de elementos metajurídicos no processo interpretativodecisório, uma degeneração ideológica da atividade interpretativa (ABBOUD; LUNELLI, 2015, p. 25).

Para Santiago, Dias e Sá (2019, p. 447), quando se analisa a abordagem do tema em culturas jurídicas diversas a caracterização de uma atividade judicial como ativista fica ainda mais complicada e, no Brasil, o problema ocorre de forma ainda mais grave em razão do costume jurídico de se importar teorias estrangeiras sem a devida adequação com a realidade local.

Copatti (2016, p. 2440) acredita que o ativismo judicial brasileiro também encontra margem nas da judicialização da política, um problema derivado da instabilidade democrática, mas que acaba permitindo a atuação de juízes e tribunais como legisladores, extrapolando suas competências ao interpretar e atribuir sentidos aos textos conforme a sua própria subjetividade.

Portanto, é importante lembrar que as explicações que envolvem o tema não encontram uniformidade na doutrina. Enquanto para alguns o ativismo judicial é uma afronta ao Estado Democrático de Direito, para outros é um meio de obtenção de justiça e é justamente neste ponto que a confusão com a instrumentalidade se inicia. Por ora, ressalta-se apenas que, assim como afirmaram os autores, o ativismo é um problema hermenêutico e não uma construção teórica, como é o caso da instrumentalidade.

No debate contemporâneo a centralidade da jurisdição, proposta pela teoria instrumentalista, indica a necessidade de aumentar-se a importância dedicada ao estudo da atividade jurisdicional, razão pela qual não parece adequada a percepção reduzida da centralidade da jurisdição como responsável pelo surgimento do ativismo judicial.

\section{A INSTRUMENTALIDADE COMO MÉTODO PARA EFETIVAR O ACESSO À JUSTIÇA}


Dinamarco propõe "a abertura do sistema processual aos influxos do pensamento publicista e solidarista vindo da política e da sociologia do direito" (2005, p. 11). Por meio da reconstrução do pensamento dos processualistas modernos, pretendia formar uma nova mentalidade capaz de desmistificar as regras e formas do processo para otimizar o sistema em alcance da efetividade processual:

O objetivo central desta obra é levar aos estudiosos do processo civil a minha proposta de revisão do modo como encaram a sua ciência e os institutos do universo de suas investigações. É tempo de integração da ciência processual no quadro das instituições sociais, do poder e do Estado, com a preocupação de definir funções e medir a operatividade do sistema em face da missão que lhe é reservada. Já não basta aprimorar conceitos e burilar requintes de uma estrutura bem engendrada, muito lógica e coerente em si mesma, mas isolada e insensível à realidade do mundo que deve estar inserida. (DINAMARCO, 2005, p. 11)

À primeira vista, a proposta de Dinamarco parece mesmo se confundir com o fenômeno do ativismo judicial: concretização da justiça, desmitificação das regras processuais e abertura do sistema processual aos influxos do pensamento vindo da política e da sociologia do direito. Essa confusão de conceitos, mediante a identificação de algumas características comuns, faz parte do processo de democratização do sistema jurídico iniciado a partir da Constituição Federal de 1988, mas isso não significa que o ativismo judicial surgiu a partir do instrumentalismo e nele se sustenta.

Uma avaliação histórica do constitucionalismo brasileiro permite perceber que a abertura do sistema processual aos influxos do pensamento publicista não configura uma construção teórica inovadora de Dinamarco. Da leitura inicial de sua obra, Dinamarco explica a sua proposta em 1986, alguns anos antes da Constituição Federal de 1988 entrar em vigor. Possivelmente, encontrou justificativas naquele momento constitucional para repensar a função do processo no sistema jurídico.

Assim, trata-se de uma constatação da realidade que o fez pensar sobre a função teleológica do processo como um instituto não apenas processual, mas um instrumento social para a efetividade do princípio constitucional do acesso à justiça, essencial para a concretização de direitos. Nesse sentido, o processo deveria ser compreendido como uma ferramenta da atividade jurisdicional e não poderia ser desvinculado de sua finalidade. Ainda na apresentação de sua proposta, Dinamarco manifesta: 
Espero que, revelando as tendências da atualidade e destacando os objetivos a realizar, o presente estudo seja capaz de alguma contribuição trazer à formação do novo pensamento preconizado e consequente aperfeiçoamento do próprio mecanismo processual - porque o processo e suas teorias e sua técnica têm a sua dignidade e o seu valor dimensionados pela capacidade, que tenham, de propiciar a pacificação social, educar para o exercício e respeito aos direitos, garantir as liberdades e servir de canal para a participação democrática. (DINAMARCO, 2005, p. 12).

Contudo, apesar desse viés teleológico e dessa integração social, a proposta de Dinamarco não pode ser identificada com um modelo condutor de posturas ativistas na magistratura, como propuseram Abboud e Lunelli (2015). Por ser baseada em parâmetros técnicos, a instrumentalidade afasta-se do subjetivismo típico do ativismo judicial e aproximase dos padrões normativos e constitucionais do ordenamento jurídico.

Primeiramente, há de se considerar que a teoria da instrumentalidade do processo é amplamente reconhecida na doutrina brasileira, sendo inclusive identificada como a terceira fase de desenvolvimento histórico do direito processual. Ou seja, a instrumentalidade é explicada pela doutrina processual como uma etapa da evolução do direito processual civil brasileiro como ciência.

Portanto, desde quando foi publicada até os dias atuais, a obra de Dinamarco representou um marco teórico na ciência processual e acompanhou a evolução do Estado constitucional brasileiro, de modo que descabe a atribuição à teoria instrumentalista - idealizada em momento histórico distinto - os problemas hoje identificados no ativismo judicial.

Como um sintoma da má utilização das possibilidades metodológicas trazidas pelo constitucionalismo contemporâneo, o ativismo judicial é identificado como uma prática dos juízes em conferir justiça mediante a aplicação irrestrita de princípios para a solução do caso concreto. Dessa forma, não foi a evolução da ciência processual que instituiu um ambiente favorável ao desenvolvimento do ativismo judicial. Este se configura como um problema causado pela ausência de compreensão das limitações metodológicas do sistema que o jurista deveria dominar.

Posteriormente, é preciso destacar que a ideia da instrumentalidade se adequa ao princípio constitucional do acesso à justiça, especialmente por enfatizar que o processo não é um fim em si mesmo e somente existe para proporcionar a prestação jurisdicional. Como terceira etapa de desenvolvimento da evolução histórica do direito processual, a fase instrumentalista é caracterizada pela concentração dos estudos em temas como acesso à justiça e efetividade do processo (DIDIER JR., 2015). 
Percebe-se que a teoria da instrumentalidade revela um grau de utilidade conferido à existência do processo. O processo passa a ser visto como um instrumento da justiça, cujas regras de nada servem se não proporcionarem a obtenção do direito material. Afinal, no Estado Constitucional Democrático de Direito, "se o juiz não atua com o intuito de materializar este desiderato, presta, quando muito, jurisdição na forma, mas não no conteúdo." (MEDINA, 2015, p. 143).

Por meio deste raciocínio chega-se ao terceiro argumento contrário às ideias dos autores: o ativismo não deve ser atribuído à teoria instrumentalista porque Dinamarco (2005) estabeleceu relações de interdependência entre aquilo que por ele foi denominado de escopos do processo, fixando os propósitos norteadores da atividade jurisdicional por meio de um raciocínio teleológico. Essa conclusão demanda melhor conhecimento do aspecto técnico, cuja explicação será agora detalhada.

Ao ser utilizado como um meio, o processo tem sua legitimidade apoiada na capacidade de realizar objetivos. Nesse aspecto, faz-se indispensável transcrever as exatas palavras:

\begin{abstract}
A tomada de consciência teleológica, incluindo especificação de todos os objetivos visados e de como se interagem, constitui peça importantíssima no quadro instrumentalista do processo: sem compreender a sua instrumentalidade assim integralmente apoiada nessas colunas, não se estaria dando a ela a condição de verdadeira premissa metodológica, nem seria possível extrair dela quaisquer consequências cientificamente úteis ou aptas a propiciar a melhoria do serviço jurisdicional. (DINAMARCO, 2005, p. 181-182).
\end{abstract}

A partir dessa explicação fica perceptível que a jurisdição, por meio do processo, possui um escopo jurídico, consistente na atuação da vontade concreta do direito; um escopo social, identificado pelo autor como a capacidade de educar e pacificar com justiça; e, por fim, um escopo político, derivado da atuação da jurisdição como poder estatal.

Dentro do escopo político, três pontos são designados importantes pelo autor: poder, liberdade e participação. Desse modo, o escopo político da jurisdição deve permitir o equilíbrio do exercício do poder e a concretização da liberdade, mas deve ainda possibilitar a participação como um valor democrático legitimador do processo político.

É por meio da dinâmica de aplicação dos escopos processuais que Dinamarco concretiza a teoria da instrumentalidade, revelando que o direito e o processo estão ligados pela unidade dos escopos processuais sociais e políticos, possibilitando a visão do processo, interpretação de suas normas e solução dos seus problemas à luz do direito material e dos seus valores basilares. 
Fica claro que há necessidade de observação integral de todos os escopos desenvolvidos na teoria, sob pena da instrumentalidade não resultar em utilidade. Ou seja, é preciso perceber que o próprio sentido de instrumentalidade processual exige do intérprete uma postura de identificação do processo como uma ferramenta de obtenção do direito material mediante a observância dos critérios já instituídos pelo sistema jurídico, caso contrário o processo não servirá de instrumento do direito, mas sim de ferramenta individual para práticas interpretativas arbitrárias.

Isto é de extrema importância na aplicação da teoria de Dinamarco porque a fixação do escopo exclusivamente jurídico não permite conferir a importância da destinação social e política do exercício da jurisdição, razão pela qual devem ser considerados de forma conjunta.

\title{
3.1.DA INEXISTÊNCIA DE ESPAÇO PARA $O$ ATIVISMO NO INSTRUMENTALISMO
}

Por tudo que já foi abordado até o momento, constata-se que o ativismo revela "um perfil decisório autoritário porque, usualmente, discricionário, na medida em que fruto da convicção pessoal de quem julga ao ignorar que o sentido não está à disposição do intérprete.” (STRECK; SALDANHA, 2013, p. 404).

Mediante uma análise mais detida da obra de Dinamarco, fica perceptível a preocupação do autor com o exercício do poder dos juízes dentro dos parâmetros trazidos pelos princípios e normas constitucionais. Ao tratar sobre a relação existente entre a Constituição e o processo, o autor afirma:

\begin{abstract}
A Constituição age sobre o processo, garantindo-lhe os princípios básicos, para que o processo possa, depois, atuar convenientemente os preceitos e garantias que ela própria contém e que proteja sobre todo o ordenamento jurídico. A bipolaridade dessas influências associa-se, naturalmente, ao reconhecimento do poder que os juízes exercem, como guardas da Constituição e responsáveis pela sua interpretação fiel e cumprimento estrito. Assim, inserido nas estruturas estatais do exercício do poder, o juiz é legítimo canal através de que o universo axiológico da sociedade impõe as suas pressões destinadas a definir e precisar os sentidos dos textos, a suprir-lhes eventuais lacunas e a determinar a evolução do conteúdo substancial das normas constitucionais. (DINAMARCO, 2005, p. 47).
\end{abstract}

Evidencia-se, portanto, a preocupação de Dinamarco com os princípios constitucionais do processo, pois reconhece a atuação da Constituição e a orientação da atuação do juiz por meio de seus princípios. Reconhecer que o juiz é um legítimo canal do universo axiológico da 
sociedade não lhe permite funcionar como antena para construir suas decisões de forma autoritária.

Nesse aspecto, vale ressaltar o entendimento de Dinamarco no sentido de um necessário posicionamento do estudioso do processo quanto à relação existente entre o direito material e processo, destacando-se as diferenças existentes nas teorias dualista e unitária, capazes de direcionar o modo como o processualista entende o direito substancial e a função exercida pelo processo. (DINAMARCO, 2005).

Aliás, este é um outro ponto essencial para perceber que a instrumentalidade não consegue dar suporte teórico ao ativismo judicial. Dinamarco (2005, p. 236) não compactua com a ideia de que os direitos só são efetivos quando afirmados pela via do processo, não passando de mera promessa antes disso. Segundo o autor, as insatisfações e as incertezas partem de dados sociológicos e não jurídicos, pois a questão jurídica posta em juízo é trazida do contexto social para a vida jurídica do processo, mas não se pode cometer a impropriedade de inserir na análise jurídica algo que não pertence ao campo do direito.

Dessa forma, fica nítido que Dinamarco não se filia à tese unitária e constitutiva, pois nega a participação ativa do juiz na construção formal do preceito positivo e concreto por meio de uma sentença criativa de direitos e obrigações: "na realidade, se criação houvesse não seria por obra exclusiva do juiz, porque o processo não é feito só por ele: resulta de uma cooperação com os sujeitos interessados, os quais são admitidos a participar e a influir efetivamente no teor dos resultados." (DINAMARCO, 2005, p. 237).

Portanto, torna-se insustentável atribuir ao autor da instrumentalidade do processo algum tipo de influência no fenômeno do ativismo judicial hoje identificado. O juiz ativista pretende justamente o oposto de Dinamarco: criar direitos por meio de sentenças, em desacordo com as normas legais. É fundamental compreender a função da atividade jurisdicional a partir da visão dualista e declarativa adotada por Dinamarco, para assim perceber o contexto da sua teoria. Se o próprio autor é contrário à ideia de criação do direito no caso concreto, não é possível afirmar que a instrumentalidade autoriza que juízes criem direitos ainda não existentes, para assim configurar uma conduta ativista.

Para Abboud e Lunelli (2015), o problema reside na aposta de Dinamarco na sensibilidade e no sentimento do juiz para desvendar o que seria justo. Isso porque pelo instrumentalismo, diante de duas situações igualmente aceitáveis ante o texto legal, o juiz deveria escolher a que melhor satisfaça o seu sentimento de justiça. Por esse entendimento, a questão fica mais uma vez na consciência do juiz e "essa visão politicamente correta do direito 
que ama a justiça, mas odeia a Constituição, busca embasar sua posição no argumento pseudoetimológico, afirmando que sentenciar vem de sentimento" (ABBOUD; LUNELLI, 2015, p. 29).

De fato, a preocupação com a segurança jurídica é ainda um dos principais fatores apontados como problemas derivados do ativismo, pois a percepção pessoal do julgador contamina a interpretação da lei com sua subjetividade. Mas ainda que a certeza jurídica, revelada pela busca da verdade, tenha a ver com uma atividade subjetiva do juiz traduzida na sua convicção formada acerca da ocorrência dos fatos, esta convicção deve ser realizada de modo racional, mediante a assunção calculada de riscos porque "a lei escrita dá parâmetros e limita as possíveis dúvidas, mas nem assim estas ficam definitivamente afastadas." (DINAMARCO, 2005, p. 292).

Nesse sentido, quando o autor destaca a necessidade de se aplicar os escopos do processo como técnica processual, explica que a tarefa de interpretar os textos, colher precedentes, observar as posições da doutrina e considerar princípios gerais é, na verdade, atividade instrutória, preparatória para o juízo a ser emitido a respeito da pretensão deduzida (DINAMARCO, 2005). Dessa forma, a verdade concreta da lei substancial é revelada pelo juiz no dispositivo da sentença. Ainda nas palavras do autor:

\begin{abstract}
Nesse juízo, a fidelidade ao ordenamento jurídico depende estreitamente da correta percepção dos fatos, porque toda norma jurídica prevê a ocorrência de fatos e sua disposição se aplica na medida e sob a condição de que os fatos previstos tenham tido efetiva ocorrência; e depende, ainda, da correta determinação do sentido da norma (mediante interpretação adequada dos textos legais), seja quanto à hipótese de incidência (fattispecie), seja quanto ao preceito ditado (sanctio legis). (DINAMARCO, 2005, p. 285).
\end{abstract}

Entretanto, há casos especiais em que Dinamarco (2005) permite que a fidelidade à vontade concreta da lei seja mitigada para fazer preponderar a função de pacificação social da jurisdição. Mas são situações especiais previstas na lei processual, como no caso da antecipação da tutela e outras regras processuais que possibilitam a abreviação de juízos e a economia da instrução. Ou seja, ainda que haja uma certa mitigação da vontade da lei, essa liberdade conferida ao juiz ainda permanece vinculada ao princípio da legalidade, pois somente poderá atuar dentro das especificidades previstas na lei.

Diante dessa metodologia proposta, a instrumentalidade não produz um juiz antena, como definido por Abboud e Lunelli (2015, p. 27). Quando Dinamarco afirma que as convicções sociopolíticas do juiz devem refletir as aspirações da sociedade, externa apenas que 
o juiz não deve ser indiferente às escolhas axiológicas desta mesma sociedade para apegar-se de forma exagerada à literalidade da lei que pode levar a generalizações capazes de ignorar as peculiaridades de certos casos. Nas palavras do autor:

[...] preceitos abstratos e genéricos são construídos com vista a situações normais previstas e a partir de hipóteses de fato absolutamente claras a quem os estabelece; e a realidade da vida que chega ao juiz, no drama do processo, é muito mais complexa e intrincada, solicitando dele uma sensibilidade muito grande para a identificação dos fatos e o enquadramento em categorias jurídicas, para a descoberta da própria verdade quanto às alegações de fato feitas pelos litigantes e sobretudo para a determinação do preciso e atual significado das palavras contidas na lei. (DINAMARCO, 2005, p. 239).

Este é, precisamente, o contexto trazido pelo autor que antecede a afirmação trazida por Abboud e Lunelli. Torna-se perceptível que não se trata de uma visão subjetivista destacada da realidade normativa posta, pois Dinamarco trata do assunto dentro do capítulo relativo ao escopo jurídico da jurisdição e destaca que a peculiaridade de certos casos exige do juiz moderno uma conduta imparcial, mas não indiferente.

Há ainda de se considerar os limites materiais da causa. No processo de conhecimento, antes de sentenciar o juiz deve conhecer a causa e instruir-se de provas capazes de ajudá-lo na construção de sua decisão. Como um instrumento à serviço do direito material o processo serve ao juiz, que deve buscar na verdade processual o adequado juízo de valor que a sociedade atribui aos fatos. É nesse contexto que Dinamarco atribui ao juiz o aspecto axiológico de sua função ao não se esquivar dos valores sociais capazes de influenciar na efetividade de sua decisão para a causa.

Conforme já visto, a teoria da instrumentalidade só terá utilidade se todos os seus escopos forem observados de forma conjunta. Desse modo, ainda que Dinamarco entenda a abertura da interpretação para que o juiz revele o sentido da lei conforme seu sentimento de justiça, essa concepção em nada corresponde à discricionariedade para que o juiz decida conforme seu posicionamento ideológico, porque há, necessariamente, que observar os limites do poder, trabalhados pelo autor no escopo político da jurisdição:

Ao juiz não é lícito trazer para as decisões as suas preferências pessoais, senão canalizar os sentimentos da nação e, mediante sua sensibilidade a eles, buscar o sentido das normas; os desvios das decisões que se afastam da real vontade do direito podem ser devidos a erros ou arbitrariedades do juiz ou à conduta das próprias partes, mas a sua ocorrência situa-se no campo dos fenômenos e não infirma a assertiva, aqui reiterada, de que ao juiz não compete a criação do direito do caso concreto. (DINAMARCO, 2005, p. 389). 
Portanto, não há como afirmar qualquer atividade solipsista do juiz quando a própria teoria tem por base três finalidades com fundamento constitucional para aprimorar o sistema processual e garantir a efetividade do processo: a ampla defesa, a inafastabilidade do controle jurisdicional e a igualdade de oportunidade entre as partes. Para Dinamarco (2005), a consciência da instrumentalidade constitui o terceiro momento metodológico da ciência processual porque possibilita que o processualista se torne sensível aos problemas jurídicos, sociais e políticos, de conotação teleológica.

Essa visão parece se amoldar à ideia do constitucionalismo garantista. A transformação do paradigma original do positivismo jurídico mudou a natureza da jurisdição e da ciência jurídica, porque já não corresponde a uma aplicação de uma lei qualquer, mas também a assunção um papel crítico acerca de sua possível deficiência.

Contudo, para que não se confunda o ativismo com o garantismo - do mesmo modo que se confundiu com a instrumentalidade -é importante saber identificar o problema hermenêutico criado pelo ativismo judicial. Por vezes, a dificuldade de identificação desta falha no processo hermenêutico pode transformar uma decisão garantista, que tenha se utilizado da teoria da instrumentalidade do processo, em uma decisão discricionária, derivada de uma interpretação solipsista.

Isso porque os equívocos conceituais e os problemas decorrentes de práticas ativistas carecem da compreensão do fenômeno hermenêutico e da adoção de uma teoria do direito adequada aos desafios da sociedade contemporânea, em que normas constitucionais são dotadas de força normativa. (SANTIAGO; DIAS; SÁ, 2019, p. 458).

Dessa forma, é importante perceber que o constitucionalismo garantista introduz uma dimensão substancial na democracia em razão das garantias primárias de direitos fundamentais da Constituição, de modo que a legitimidade para o exercício do poder está condicionada não só às regras que disciplinam o poder de forma majoritária, mas também às regras que condicionam a sua substância (FERRAJOLI, 2008).

Pugliesi e Brandão (2019) consideram a existência de uma concepção flexível das normas jurídicas, vez que a sociedade contemporânea incorporou expressões vagas considerando, especialmente, a inserção social dos indivíduos como parte da construção social. Por esse motivo, sempre há certa poluição na concepção das normas jurídicas, pois a atividade humana é um fenômeno enraizado em processos comunicativos capazes de modificar e aperfeiçoar esse fenômeno. O mundo não é um dado imodificável, mas uma construção em constante transformação, de acordo com a situação do observador. 
Nesse aspecto, é importante ressaltar que os limites devem ser postos pelo sistema jurídico, pois pode ser visto como um resultado de promessas implícitas que definem o funcionamento da sociedade, de modo que para além de procedimentos formais há expectativas sociais que esperam ser preenchidas. (PUGLIESI; BRANDÃO, 2019).

Desse modo, o aspecto axiológico não deve ser evitado pelo juiz, mas sim enfrentado. As Constituições modernas não se limitam a dizer estaticamente o que é o direito, mas estabelecem um programa de reformas em direção ao futuro, de modo que a atividade de interpretação do juiz para fazer atuar a norma constitucional é acentuadamente discricionária (CAPPELLETTI, 1992).

Todavia, a discricionariedade e a axiologia não são definidas segundo valores pessoais do juiz. "O garantismo reforça a responsabilidade ética do operador do direito" (STRECK; SALDANHA, 2013, p. 414) e a Constituição seria o paradigma hermenêutico capaz de proporcionar a filtragem e estabelecer a validade de normas infraconstitucionais.

\section{CONCLUSÃO}

Quando Dinamarco lançou a teoria da instrumentalidade do processo, havia uma prevalência da doutrina no sentido de valorizar a autonomia do direito processual como ciência, razão pela qual os estudos se concentravam no estabelecimento de aspectos técnicos processuais, mediante uma perspectiva interna. A teoria de Dinamarco inaugurou uma nova fase na ciência processual porque preocupou-se em pensar a atividade jurisdicional voltada para a sua finalidade.

Entretanto, entender o processo como um instrumento não significa ignorar a existência do Estado de Direito para respaldar o desprezo dos juízes pelos textos legais. Essa conduta, se compreendida como ativismo judicial, sequer poderia ser aceitável no ordenamento jurídico, pois estaria fulminada de qualquer efetividade a decisão judicial formada fora dos parâmetros traçados pelo Estado de Direito

Verificou-se que Dinamarco não estabelece liberdade para o juiz construir sua decisão sem qualquer observância metodológica. A teoria da instrumentalidade não permite que o juiz não exerça o seu dever de fundamentação ou que estabeleça decisões fora dos parâmetros estabelecidos pelo ordenamento jurídico, pois os escopos político e jurídico estabelecem os limites capazes de conter a abertura proporcionada pelo escopo social. 
Por reconhecer a existência do Direito antes mesmo do processo, Dinamarco entende que o direito material é suficiente para impor condutas, o que se contrapõe ao ativismo judicial, que permite compreender a ideia de que o juiz construirá o direito na sua decisão, de modo criativo e discricionário. Para a teoria da instrumentalidade o processo utilizado como instrumento da jurisdição, que é via secundária, devendo o juiz atuar no processo observando a cooperação entre as partes e princípios constitucionais pertinentes ao devido processo legal.

De fato, há certa indefinição na atividade jurisdicional brasileira quanto aos critérios de interpretação e técnica - ou mesmo atécnica - de argumentação jurídica a ser apresentada para a solução de um caso concreto. Nesse aspecto, o estudo de Georges Abboud e Guilherme Lunelli foi de absoluta relevância, mas demonstra uma pequena parcela do problema porque atribui ao instrumentalismo um sintoma que deriva da complexidade de mudanças vivenciadas pelo constitucionalismo contemporâneo.

Desse modo, é possível afirmar que o ativismo judicial tem sua origem em um problema hermenêutico, mas compreender que é um fenômeno é estimulado pela teoria da instrumentalidade é não atentar para a metodologia proposta por Dinamarco, para quem o processo como instrumento representa a concretização da garantia do Estado de Direito Constitucional.

\section{REFERÊNCIAS}

ABBOUD, Georges; LUNELLI, Guilherme. "Ativismo judicial e instrumentalidade do processo”. Revista de Processo, São Paulo, vol. 242, p. 21-47, 2015.

CÂMARA, Alexandre Freitas. O novo processo civil brasileiro. 2. ed. rev. atual. São Paulo: Atlas, 2016.

CAPPELLETTI, Mauro. O Controle judicial de constitucionalidade das leis no direito comparado. Trad. Aroldo Plínio Gonçalves. 2. ed. Porto Alegre: Sergio Antonio Fabris Editor, 1992.

CARNEIRO, Athos Gusmão. Jurisdição e competência. 15. ed. São Paulo: Saraiva, 2008.

COPATTI, Lívia Copelli. "A crítica hermenêutica do direito como garantia à democracia e respeito à Constituição frente ao ativismo judicial". Revista Quaestio Iuris, Rio de Janeiro, vol. 09, n. 04, p. 2421-2449.

DIDIER JR., Fredie. Curso de Direito Processual Civil: Introdução ao Direito Processual, Parte geral e processo de conhecimento. V. 1. 17. ed. Salvador: Jus Podivm, 2015. 
DINAMARCO, Cândido Rangel. A instrumentalidade do processo. 12. ed. São Paulo: Malheiros editores, 2005.

DUARTE, Écio Oto Ramos; POZZOLO, Susanna. Neoconstitucionalismo e Positivismo Jurídico: as faces da Teoria do Direito em tempos de interpretação moral da Constituição. São Paulo: Landy Editora, 2010.

FERRAJOLI, Luigi. Democracia y garantismo. Madrid: Editorial Trotta, 2008.

GALVÃO, Jorge Octávio Lavocat. O neoconstitucionalismo e o fim do Estado de Direito. São Paulo: Saraiva, 2014.

HÄRBELE, Peter. Hermenêutica constitucional: a sociedade aberta dos intérpretes da Constituição: contribuição para a interpretação pluralista e 'procedimental' da Constituição. Trad. Gilmar Ferreira Mendes. Porto Alegre: Sergio Antonio Fabris Editor, 1997, reimpr., 2002.

JORGE, Nagibe de Melo. "Ativismo judicial, discricionariedade e controle". Revista Quaestio Iuris, Rio de Janeiro, v. 07, n. 02, 2014, p. 509-532.

MARINONI, Luiz Guilherme. Curso de processo civil: Teoria Geral do Processo. v. 1. 8. ed. rev. atual. São Paulo: Revista dos Tribunais, 2014.

MEDINA, José Miguel Garcia. Direito processual civil moderno. São Paulo: Revista dos Tribunais, 2015.

PUGLIESI, Márcio; BRANDÃO, André Martins. "Norm as a promise and the problem of legitimacy". Revista Quaestio Iuris, Rio de Janeiro, v. 12, n. 01, 2019, p. 56-76.

SANTIAGO, Nestor Eduardo Araruna; DIAS, Eduardo Rocha; SÁ, Alexandre Santos Bezerra. "Direito como integridade: um caminho garantista contra o ativismo judicial". Revista Quaestio Iuris, Rio de Janeiro, v. 12, n. 02, 2019, p. 444-446.

SARMENTO, Daniel. Por um constitucionalismo inclusivo: História constitucional brasileira, teoria da constituição e direitos fundamentais. Rio de Janeiro: Lumen Juris, 2010.

STRECK, Lenio Luiz. Jurisdição constitucional e decisão jurídica. 4. ed. São Paulo: Editora Revista dos Tribunais, 2014.

STRECK, Lenio Luiz; SALDANHA, Jânia Maria Lopes. Ativismo e Garantismo na Corte Interamericana de Direitos Humanos. DIDIER JUNIOR, Fredie et al. (Coord.). Ativismo e garantismo processual. Salvador: JusPodivm, 2013, p. 395-428.

Trabalho recebido em 20 de março de 2019

Aceito em 12 de junho de 2020 